\title{
Self Potential Survey, \\ Roosevelt Hot Springs, Utah
}

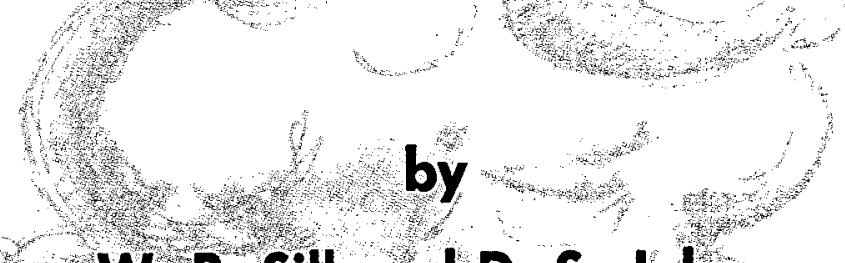

W. R. Sill and D. S. Johng

Work performed under Contract No.

DE-AC07-78ET28392

Department of Geology and Geophysics

University of Utah

Salt Lake City, Utah (USA)

January 1979

Prepared for

DEPARTMENT OF ENERGY

Division of Geothermal Energy 


\section{DISCLAIMER}

This report was prepared as an account of work sponsored by an agency of the United States Government. Neither the United States Government nor any agency Thereof, nor any of their employees, makes any warranty, express or implied, or assumes any legal liability or responsibility for the accuracy, completeness, or usefulness of any information, apparatus, product, or process disclosed, or represents that its use would not infringe privately owned rights. Reference herein to any specific commercial product, process, or service by trade name, trademark, manufacturer, or otherwise does not necessarily constitute or imply its endorsement, recommendation, or favoring by the United States Government or any agency thereof. The views and opinions of authors expressed herein do not necessarily state or reflect those of the United States Government or any agency thereof. 


\section{DISCLAIMER}

Portions of this document may be illegible in electronic image products. Images are produced from the best available original document. 


\section{NOTICE}

This report was prepared to document work sponsored by the United States Government. Neither the United States nor its agent, the United States Department of Energy, nor any Federal employees, nor any of their contractors, subcontractors or their employees, makes any warranty, express or implied, or assumes any legal liability or responsibility for the accuracy, completeness, or usefulness of any information, apparatus, product or process disclosed, or represents that its use would not infringe privately owned rights.

\section{NOTICE}

Reference to a company or product name does not imply approval or recommendation of the product by the University of Utah or the U.S. Department of Energy to the exclusion of others that may be suitable. 
This book was prepared as an accoun of work spunsored by an anency of the United States Governmen, Neither the United States Government nor anv ayency theteof, nor any of their emoloyees, makes any warranty, Express or implied. or assumas any legal fiability or responsibility for the accoracy, completeness, or usefuiness of any intornation, atoaratus, product, or process disclosed, or represents that its use would mot irfringe arivately aborat rights. Reterence herein :o any specitic

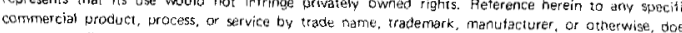
not necessarily constitute or imply its endorsemerti, recommendation, or fovoring by the United Siates Government or any agency therest. Tha views and opinions of authors oxpressed herein to no Siates covernment or any agency therest. The views and opinions of authors expressed
nacessarily state or refiect those of the United States Government or any agency thersot.

\section{SELF POTENTIAL SURVEY, ROOSEVELT HOT SPRINGS,}

\section{UTAH}

H. R. Sill

and

D. S. Johng 


\section{Abstract}

A large scale $\left(35 \mathrm{~km}^{2}\right)$ self potential (SP) survey was made at Roosevelt Hot Springs. The survey consisted of approximately 47 line-km of profiles at station spacings of $100 \mathrm{~m}$. The profiles were run using a fixed electrode and a traveling electrode out to distances of 1 to $2 \mathrm{~km}$, before advancing the fixed electrode up to the last occupied station. Repeated measurements show a standard deviation of about $\pm 6 \mathrm{mv}$, although the spread on groups of measurements might be as large as $30 \mathrm{mv}$.

Some of the SP profiles show correlations with the thermal system, having generally low values over the thermal high and the coincident resistivity low. Some of the smaller scale features appear to be associated with mapped faults. In plan view, the contoured self potential shows a character very similar to the $300 \mathrm{~m}$, dipole-dipole resistivity. The SP values are generally low, where the resistivity is low. Along the eastern margin of the system, in the vicinity of steep resistivity gradients, the contour map show a series of localized highs.

Electrokinetic (streaming potential) and thermoelectric effects are likely candidates for the sources of these self potential anomalies. The (near surface) hydrothermal clay alteration should increase the cross coupling coefficients for these two effects, although excess clay alteration may reduce the effects through the reduction in electrical resistivity.

Thermoelectric effects, combined with vertical temperature gradients or spherical or point sources below the clay alteration zone (large coupling coefficient), generally produce positive SP anomalies. Negative 
thermoelectric anomalies can be produced by point sources within the cross coupling zone (clay alteration), but this would probably be limited to relative shallow sources (less than hundreds of meters). On the other hand, electrokinetic effects combined with various spherical or point sources generally produce negative anomalies. For this reason, the electrokinetic effects might be favored as the source of the large scale low region. Other sources or geometries might be postulated for the localized highs, but their proximity to the steep resistivity gradients might suggest a cause related to the electrical structure.

$-2-$ 


\subsection{Introduction}

Self Potential (SP) measurements in geothermal areas have shown anomalous regions associated with the nearsurface thermal zones and faults thought to be fluid conduits. (Zohdy et al., 1973; Corwin, 1975; Anderson and Johnson, 1976; Zablocki, 1976; Combs and Wilt, 1976; Mabey et al., 1978; Corwin and Hoover, 1978). The signs of these anomalies have been both positive and negative.

Possible sources for these self potentials are electrokinetic effects (streaming potentials), thermoelectric effects and chemical potential diferences. Streaming potential effects (Appendix A) tend to be slightiy favored since the combination of the typical streaming potential coefficient and the force (gradient of the pressure) generally combine to produce effects of larger magnitude from buried spherical or point sources (Corwin and Hoover, 1978). However, strong near surface thermal gradients are capable of producing sizeable selfpotential anomalies (Appendix A).

By definition fluids are moving in a convective hydrothermal system and the system usually has zones of clay alteration. Clay minerals, through their larger cation exchange capacity, aid in the generation of electrokinetic and thermoelectric potentials. However, large percentages of clays and the higher conductivity of hydrothermal fluids would tend to reduce streaming potential effects through the reduction of permeability and the electrical resistivity.

The first SP measurements at Roosevelt Hot Springs were made in 1974 and consisted of a small scale survey utilizing the leapfrog method and a station spacing of $25 \mathrm{~m}$ (Ward et al., 1974). Some of the results are 
repeated here in figure 1. Several of the lines show a narrow negative anomaly of about $100 \mathrm{mv}$ amplitude. The location of the anomaly is near the top of the Opal Dome where there are fissures showing vertical banding in the opal along the trace of the Opal Dome Fault. These vertical fissures were presumeably the conduits for the thermal waters that built up the opal dome. The width of the anomaly is only slightly more than $100 \mathrm{~m}$ indicating that the source is probably quite shallow. Measurements in the vicinity of the old resort hot springs did not show any distinct small scale anomalies. During the summer of 1978 , a preliminary, large scale survey was completed. Approximately $47 \mathrm{~km}$ of SP profiles were run; most with a station spacing of $100 \mathrm{~m}$. The survey (figure 2) consisted of 5 east-west profiles and a north-south line to tie all of the profiles to a common datum. Figure 2 also shows the $300 \mathrm{~m}$ first separation, dipole-dipole apparent resistivity and the location of the common datum (home pot) point, to which all of the potential measurements are referenced. 


\subsection{Measurement Procedure}

Al1 measurements were made with $\mathrm{Cu}-\mathrm{Cu} \mathrm{SO}{ }_{4}$ (Sat.) porous ceramic pots and a high impedance digital voltmeter. The home pot location consisted of a shallow $(.5 \mathrm{~m})$ hole in which a porous pot electrode was buried, to reduce the effects of temperature fluctuations and changes in soil moisture. Measurements on the nearby surface soil varied between $+15 \mathrm{mv}$ and $+25 \mathrm{mv}$ with respect to the buried electrode. At each station location four measurements were taken on a square grid (10 $\mathrm{m}$ on a side) and the average of the four readings was taken as the observed potential. Each of the individual measurements was made in a shallow hole approximately $10 \mathrm{~cm}$ deep, so that reasonable amounts of soil moisture would be present.

The lines were run using a given fixed electrode and a traveling electrode out to distances of 1 to $2 \mathrm{~km}$, before moving the fixed electrode up to the last occupied station. This procedure helps to reduce some of the errors due to so called pot noise and drift caused by temperature changes, etc. On some occasions, at distances in excess of $1 \mathrm{~km}$, telluric noise could be observed but no attempts were made to correct for this noise other than to average over the higher frequency fluctuations.

Figure 3 shows a detailed survey out to $500 \mathrm{~m}$ from the datum electrode at intervals of $25 \mathrm{~m}$ and $50 \mathrm{~m}$. The solid dots are the four individual measurements, the open circles are the means and the horizontal bars show the standard deviations (SD). At the datum station (OW) the two repeated occupations have means a few mv apart and the SD of all eight readings is $\pm 6 \mathrm{mv}$. At station $100 \mathrm{w}$ there is a higher noise level but the means are within a few mv and the SD is about $\pm 11 \mathrm{mv}$. Station $300 \mathrm{~W}$ illustrates a case 
where the means differ by the amount of the SD $( \pm 12 \mathrm{mv})$. The overall SD is around $\pm 6 \mathrm{mv}$ al though groups of measurements can sometimes exhibit a spread of $20 \mathrm{mv}$ to $30 \mathrm{mv}$.

In figure 4 , from 0 to $1 \mathrm{kmE}$ are shown two sets of data taken several weeks apart and on opposite sides of the road. There is general agreement between the two curves in form and magnitude, although in places there are differences as large as 30mv. Also shown in figure 4 are results of another survey (Corwin and Hoover, 1978). The agreement between the two measurements is quite good, note however, that the scale factors differ by a factor of two.

Several of the lines (figure 2) intersect to form closed loops, which provides another check on the accuracy of the measurements. Investigation of the data on these lines show loop errors of around $30 \mathrm{mv}$, in distances of $5 \mathrm{~km}$ (50 stations). 


\subsection{Self Potential Data}

Figure 5 shows the profile along the road that runs parallel to $2200 \mathrm{~N}$ and then into Big Cedar Cove. This profile shows what appears to be some rather interesting correlations with the known thermal system. To the east in Big Cedar Cove, in the region of rapidly increasing resistivity the SP profile shows a general high. Over the resistivity low and region of high thermal gradients the SP is low and to the west of the Dome fault the SP returns to higher values. There are several minor features that might even be correlated with specific faults, for example the two minor lows, one associated with the fault crossing the mouth of Big Cedar Cove and the other at the fault west of the Dome Fault. Between these two faults there are minor highs associated with the Dome Fault and F1.

The profile one kilometer to the south (Figure 6 ) does not show such a distinct character, however. There is no large high to the east, but there is a suggestion of a depressed zone in the thermal area as well as some local positive areas that may be correlated with the Dome Fault and F1.

The profiles on the other lines do not in general show similar correlations. The complex nature of the SP anomaly can be seen in the contour map of figure 7. This map was compiled from all of the data, making some adjustments for the loop errors and with some "eyeball" smoothing. As can be seen from the comparison with the apparent resistivity data (figure 2 ), there is a lobate region to the west of the southern section that narrows to the north in the vicinity of 3000 to 4000 N. At the northern end there is some widening of the low region as is also seen in the apparent resistivity. On the eastern side things are more 
complicated, with a number of highs and lows in the region of the steep resistivity gradients. The lowest resistivity areas $(<10 \Omega \mathrm{sm})$ are generally regions of low SP $(<-50 \mathrm{mv})$, although there are also low areas outside of the thermal area. As a matter of fact the most negative region is in the southeast corner, up against the flank of the Mineral Range.

There are also a number of isolated positive regions, noteably a pair in the mouth of Big Cedar Cove and another central one between 3000 and $4000 \mathrm{~N}$, just to the east of the baseline. There is also the suggestion of a positive trend extending from the ridge in the southeast, to the central high (noted above) and off as a weak ridge to the northeast. Most of the producing wells are along this trend (figure 2 ) and well 25-15 is just to the southwest of the high in Big Cedar Cove. 


\subsection{Conclusions}

As with other geothermal areas, Roosevelt Hot Springs has SP anomalies associated with the near surface thermal zone. The nature of the SP pattern is complex, consisting of low areas correlating quite well with the low resistivity regions but also containing positive areas in the vicinity of some of the producing wells. The source(s) of these SP anomalies is not known, al though many have been suggested in the past. A likely candidate is the electrokinetic streaming potential because its magnitude is relatively larger for typical geological materials. It doesn't seem likely that the source(s) will be determined until much more is known about the nature of the cross coupling coefficents in materials from geothermal areas and the nature of the flows (fluids, heat etc.) in some well understood geothermal area.

Consideration of the models in Appendix A, show the expected thermoelectric anomaly, due to the large nearsurface thermal gradient, would be positive over the thermal region. The observed anomaly is generally negative over this region although there are some positive areas. On the other hand, the streaming potential anomalies for the preferred models in Appendix A would be negative over the regions ascending fluids, which would tend to favor electrokinetic effects as the source mechanism.

Also in considering what one might call an anomaly one needs to know the nature of the background SP in a "normal." area. This survey was by and large confined to the anomalous zone, however some limited measurements off the southern end seem to indicate that the Mineral Range is negative with respect to the valley with steep gradients along the range front. This is 
in agreement with some measurements in other areas showing increasing negative SP with increasing altitude (Corwin and Hoover, 1978). More measurements to the north and south of the system are needed to put the thermal anomaly region in context. 


\section{APPENDIX A}

\section{Electrokinetic Coupling}

The streaming potential effects due to the coupled flow of electrolyte and electrical current are not always intuitively obvious and therefore it is helpful to consider some simple cases. The basic equations to consider are the solvent flow equation $(A-1)$ and the coupled electric current flow equations $(A-2)$.

$$
\begin{array}{ll}
\Gamma=-k \nabla P \quad \text { (flux of electrolyte) } & A-1 \\
J=-\Gamma \nabla \phi-L p q \nabla P \quad \text { (flux of charge) } & A-2
\end{array}
$$

where

$$
\begin{aligned}
& k=\text { permeability } \\
& \sigma=\text { conductivity } \\
& L p q=\text { streaming current coefficient } \\
& P=\text { pressure } \\
& \phi=\text { electric potential } \\
& L p q / \sigma=\text { streaming potential coefficient }=\alpha
\end{aligned}
$$

Equation A-2 can be rewritten in terms of the generalized or pseudopotential $\psi$ as

$$
J=-\sigma \nabla \psi
$$

where

$$
\psi=\phi+\alpha P
$$

For no external current sources

$$
\nabla \cdot J=0
$$

and therefore $\quad \nabla^{2} \psi=0$ 
the boundary conditions are then

$$
\psi^{1}(b)-\psi^{2}(b)=\left(a_{1}-\alpha_{2}\right) P(b)
$$

from the continuity of $P$ and $\psi$ on the boundary (b), and

$$
\sigma_{1} \frac{\partial \psi_{1}}{\partial n}=\sigma_{2} \frac{\partial \psi_{2}}{\partial n}
$$

from the continuity of the normal current $(n)$ across the boundary. The current flow has two components $(A-3$ and $A-4)$ one driven by an electric potential and another due to the pressure through the streaming current coefficient.

A simple case to consider is the point source of pressure in a medium with only a contrast in the streaming potential coefficient (figure 1a). The potentials are (from A-3 through A-7):

$$
\begin{aligned}
& \psi_{1}=\left(\alpha_{1}-\alpha_{2}\right) \frac{P_{0} a}{2} \frac{1}{\left[r^{2}+(Z 0-Z)^{2}\right]^{\frac{1}{2}}} \\
& \phi_{1}=\psi_{1}-\alpha_{1} P_{0} a \frac{1}{\left[r^{2}+(Z 0+Z)^{2}\right]^{\frac{1}{2}}} \\
& \psi_{2}=\left(\alpha_{1}-\alpha_{2}\right) \frac{P_{0} a}{2} \frac{1}{\left[r^{2}+(Z 0+Z)^{2}\right]^{\frac{1}{2}}} \\
& \phi_{2}=\psi_{2}-\alpha_{2} P_{0} a \frac{1}{\left[r^{2}+(Z 0+Z)^{2}\right]^{\frac{1}{2}}}
\end{aligned}
$$


The total current flow pattern for a positive pressure source and $\alpha_{1}>\alpha_{2}$ is shown in figure $1 b$. Note that even though the pressure driven streaming current is radial outwards, from medium 1 into 2 , that the total current circulates from medium 2 into medium 1 . Consideration of the electrically driven currents $(-\sigma \nabla \phi)$ shows that they are set up so as to drive return currents to the regions of charge deficiency at the pressure source and/or the interface (depending on the magnitudes of $\alpha_{1}$ and $\alpha_{2}$ ). The direction of the current flow will be reversed for $\alpha_{1}<\alpha_{2}$, however note that the sign of the (real) electric potential (A-11) remains negative. In this case then we see that the potential $\phi_{2}$ (the real electric potential that would be measured in medium 2) remains the same no matter what the relative magnitudes of $\alpha_{1}$ and $\alpha_{2}$, and in spite of the reversal in the direction of the total current.

The above example is geometrically quite simple but it does illustrate some subtle and perhaps unexpected effects. A more realistic model would include the air-earth interface. Nourbehecht (1963) considered such a model. The boundary condition he used was that the pressure was zero on the interface and this was accomplished by using an image pressure source of opposite sign in the air (figure 2a). However; this distribution of pressure sources gives a nonzero pressure gradient at the surface and implies a flow (a spring) across the interface. If a like pair of pressure sources (figure $2 b$ ) are utilized, there is no flow across the interface and the surface is not an equipotential. This would correspond to the air-earth interface being an impermeable boundary. This might correspond more closely to the actual flow in a homogeneous earth, where a perturbation in the water table would lead to a more or less horizontal 
flow just below the water table and away from the pressure source (figure 2C).

Considering the model in figure 2.d, with only a contrast in streaming potential coefficients, Nourbehechts' pressure model with a negative sign for the image pressure $(P(z=0)=0)$ gives for the electrical potential on the surface.

$$
\phi_{1}(r, Z=0)=\left(\alpha_{1}-\alpha_{2}\right) P O^{a}\left(\frac{1}{\left[r^{2}+Z 0^{2}\right]^{\frac{1}{2}}}-\frac{1}{\left[r^{2}+(Z 0+2 d)^{2}\right]^{\frac{1}{2}}}\right)
$$

This potential can be positive or negative depending on the magnitudes of $\alpha_{1}$ and $\alpha_{2}$. If the image source has the same $\operatorname{sign}(d P / d z \mid z=0=0)$ the potential on the surface is

$$
\phi_{1}(r, Z=0)^{4}=-\left(\alpha_{1}+\alpha_{2}\right) \cdot P_{0} a \frac{1}{\left[r^{2}+Z 0^{2}\right]^{\frac{1}{2}}}+\alpha_{1} P_{0} a \frac{1}{\left[r^{2}+(Z 0+2 d)^{2}\right]^{\frac{1}{2}}}
$$

this potential is always negative $\left(P_{0}>0\right)$ no matter what the relative magnitudes of $\alpha_{1}$ and $\alpha_{2}$. These two models give quite different results. The latter model $(A-13)$, which probably represents the real flow more accurately, always produces a negative anomaly over a positive pressure source. It should also be noted that A-13 gives an anomaly even for a 
homogeneous earth $\left(\alpha_{1}=\alpha_{2}\right)$, while Nourbehecht's model (A-12) does not.

Bogoslovsky and Ogilvy (1973) reported a positive self potential anomaly over a shallow pumping well (negative pressure source) which would agree with equation $\mathrm{A}-13$. For the measured pressure gradient this would require a streaming potential coefficient of about $30 \mathrm{mv} / \mathrm{atm}$, which is not an unreasonable number.

Thermoelectric Coupling

The coupled equations for this case are

$$
\begin{aligned}
& \Gamma_{h}=-K \nabla T \quad \text { (heat Flux) } \\
& J=-\sigma \nabla \phi-\text { Lhq } T \text { (charge Flux) }
\end{aligned}
$$

where

$$
\begin{aligned}
& K=\text { thermal conductivity } \\
& L_{h q}=\text { cross coupling coefficient between temperature and charge } \\
& T=\text { temperature } \\
& \phi=\text { electric potential }
\end{aligned}
$$

These equations can be solved for the coupled flows as was done for the electrokinetic coupling with the substitution of $T$ for $P, K$ for $k$ and thermoelectric potential coefficient $(c=L h q / \sigma)$ for $\alpha$.

the boundary condition at the air-earth interface in the case of heat flow is more appropriately one where the surface is an equipotential and a flux of heat is allowed across the interface. The point source electrokinetic models, using Nourbehecht's (1963) boundary condition are then appropriate for studying the thermoelectric effects. The results of those models can then be used by making the substitution noted above. 
Another case of interest in thermoelectric studies is the anomaly caused by a change in properties in the presence of a strong vertical temperature gradient. Nourbehecht (1963) gave several samples of the effects due to vertical contacts and dikes in the presence of vertical chemical potential gradients and the results are easily adapted to the thermal problem.

Figure $3 a$ shows the geometry of a vertical contact in the presence of a vertical temperature gradient expressed as

$$
T(Z)=T_{0}\left(1-e^{-k Z}\right)
$$

Taking To $=250^{\circ} \mathrm{C}$ and $k^{-1}=500 \mathrm{~m}$ we would have a nearsurface gradient of $500^{\circ} \mathrm{C} / \mathrm{km}$ and a temperature at depths greater than $1 \mathrm{~km}$ of about $250^{\circ} \mathrm{C}$. These values are in reasonable agreement with data from Roosevelt Hot Springs.

Using the thermal model of A-16 we can solve for the electrical potential on the surface

$$
\phi_{1}(x, z=0)=-\phi_{2}=\left(c_{1}-c_{2}\right) \text { To }(.5-B(x))
$$

where

$$
\begin{aligned}
& B(x)=\frac{1}{\pi}\left(C_{j}(k x) \sin k x-s_{2}(k x) \cos k x\right) \\
& C_{j}(k x)=-\int_{k x}^{\infty} \frac{\cos t}{t} d t, S_{j}(k x)=-\int_{k x}^{\infty} \frac{\sin t}{t} d t
\end{aligned}
$$

The normalized potential $\left(\phi /\left(c_{1}-c_{2}\right) T_{0}\right)$ is plotted in figure $3 b$. For our thermal model $k x=1$ at $x=500 m$ so the anomaly would extend for several $\mathrm{km}$ 
horizontally. Thermoelectric coefficients are often of the order of several tenths of a mv/ ${ }^{\circ} \mathrm{C}$, so that anomalies of the order of $50 \mathrm{mv}$ could be possible. The anomaly would be positive over the region with the stronger thermoelectric coefficient. Since the hydrothermal system is often covered by a near surface zone of clay alteration and since clays generally tend to increase the cross coupling coefficients one might expect to get positive anomalies.

of course this is an extremely simple model, a better one might use a dikelike body rather than a vertical contact. The results of Nourbehecht's (1963) calculations show that for a vertical dike with $k t=1$ ( $t=$ thickness $=500 \mathrm{~m}$ ) the maximum value of the anomaly would be reduced by about $50 \%$ compared to the single vertical contact. 


\section{REFERENCES}

Anderson, L.A. and Johnson, G.R.; 1976, Application of the self-potential method to geothermal exploration, in Long Valley California, $\mathrm{J}$. Geophys. R., 81, p. 1527 .

Combs, J. and Wilt, M.; 1976, Telluric mapping, telluric profiling and self-potential surveys of the Dunes geothermal anomaly, Proceedings, Second United Nations Symposium on the Development and Use of Geothermal Resources, V2, p. 917.

Corwin, R.F.; 1975, Use of the self-potential method for geothermal exploration, Lawrence Berkley Laboratory Report, LBL-3235, UC-11, TID-450-R62.

Corwin, R.F. and Hoover, D.B.; 1978, The self-potential method in geothermal exploration, Lawrence Berkley Laboratory report, LBL-7075.

Mabey, D.R., Hoover, D.B., O'Donnell, J.E. and Wilson, C.W.; 1978, Reconnaissance geophysical studies of the geothermal system in southern Raft River Valley, Idaho, Geophysics, 43, 1470.

Nourbehecht, B.; 1963, Irreversible thermodynamic effects in inhomogeneous media and their application in certain geoelectric problems, Ph.D. thesis, MIT, Cambridge Mass.

Ward, S.H., Brown, F.H., Cook, K.L., Nash, W.P., Parry, W.P., Sill, W.R., Smith, R.B., and Whelan, J.A.; 1974, Progress report on NSF Grant no. GI -43741 .

Zablocki, C.J., 1976, Mapping thermal anomalies on an active volcano by the self-potential method, Proceeding second United Nations symposium on the Development and use of Geothermal resources, V2, p. 1299.

Zohdy, A.A.R., Anderson, L.A. and Muffler, L.J.P.; 1973, Resistivity, self-potential and induced polarization surveys of a vapor-dominated geothermal system, Geophysics, 38, 1130 . 


\section{List of Figures}

Figure 1. Small scale SP survey in the vicinity of the Opal Dome, Roosevelt Hot Springs. From Ward et al. (1974).

Figure 2. Map of the Roosevelt Hot Springs Area showing the locations of $\mathrm{SP}$ lines and the $300 \mathrm{~m}$, dipole-dipole apparent resistivity.

Figure 3. Detailed SP survey along $2200 \mathrm{~N}$ Road. The datum station is at OW. Solid dots are individual measurements, the open circles are the means of 4 readings and the bars show the standard deviations.

Figure 4. Comparisons of several sets of measurements along the $2200 \mathrm{~N}$ road. Solid dots and crosses the results of measurements for this report and the open circles after Corwin and Hoover (1978). The arrows show the locations of faults $(F)$.

Figure 5. SP profile along $2200 N$ road compared with the thermal gradient profile $(30-60 \mathrm{~m})$ and the $300 \mathrm{~m}$ dipole-dipole apparent resistivity.

Figure 6. SP profile along 1000N line.

Figure 7. Contour map of the self potential at Roosevelt Hot Springs. Contour values in millivolts.

\section{Appendix A}

Figure 1a. Geometry for the case of a point pressure source and interface.

Figure 1b. Current flow pattern (arrows) and equipotentials (dashed) for the geometry in figure la.

Figure 2a. Geometry of point sources and flow pattern for $p=0$ on the air-earth interface.

Figure 2b. Geometry of point sources and the flow pattern for no flow across the air-earth interface.

Figure 2c. Probable flow, with a perturbation in the water table.

Figure 2d. Geometry of point sources for the case of a layer over a half space.

Figure 3a. Geometry for a vertical contact and a vertical temperature gradient.

Figure $3 b$. The thermoelectric potential on the surface for the model in Figure $3 a$. 


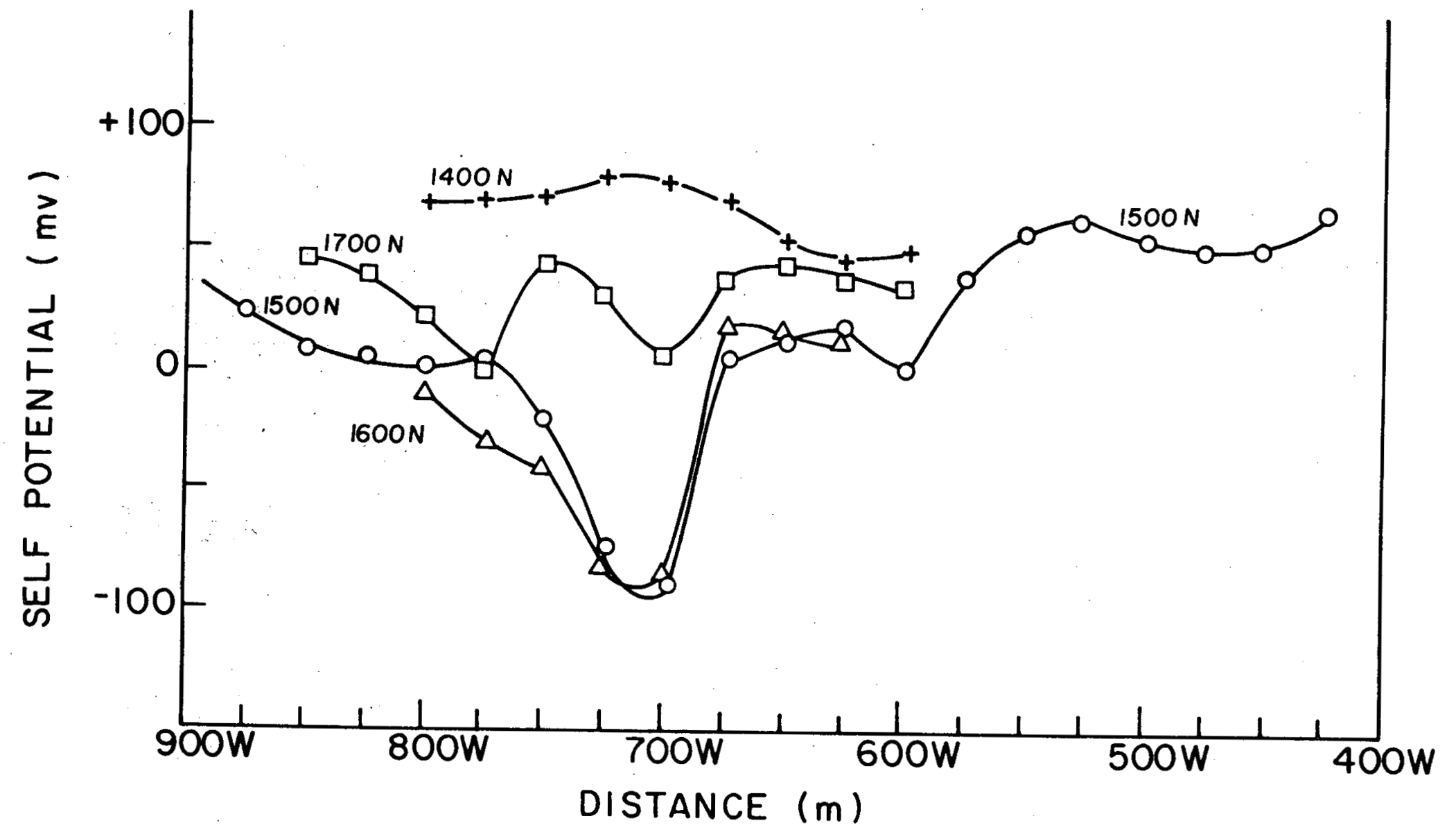

Figure 1 


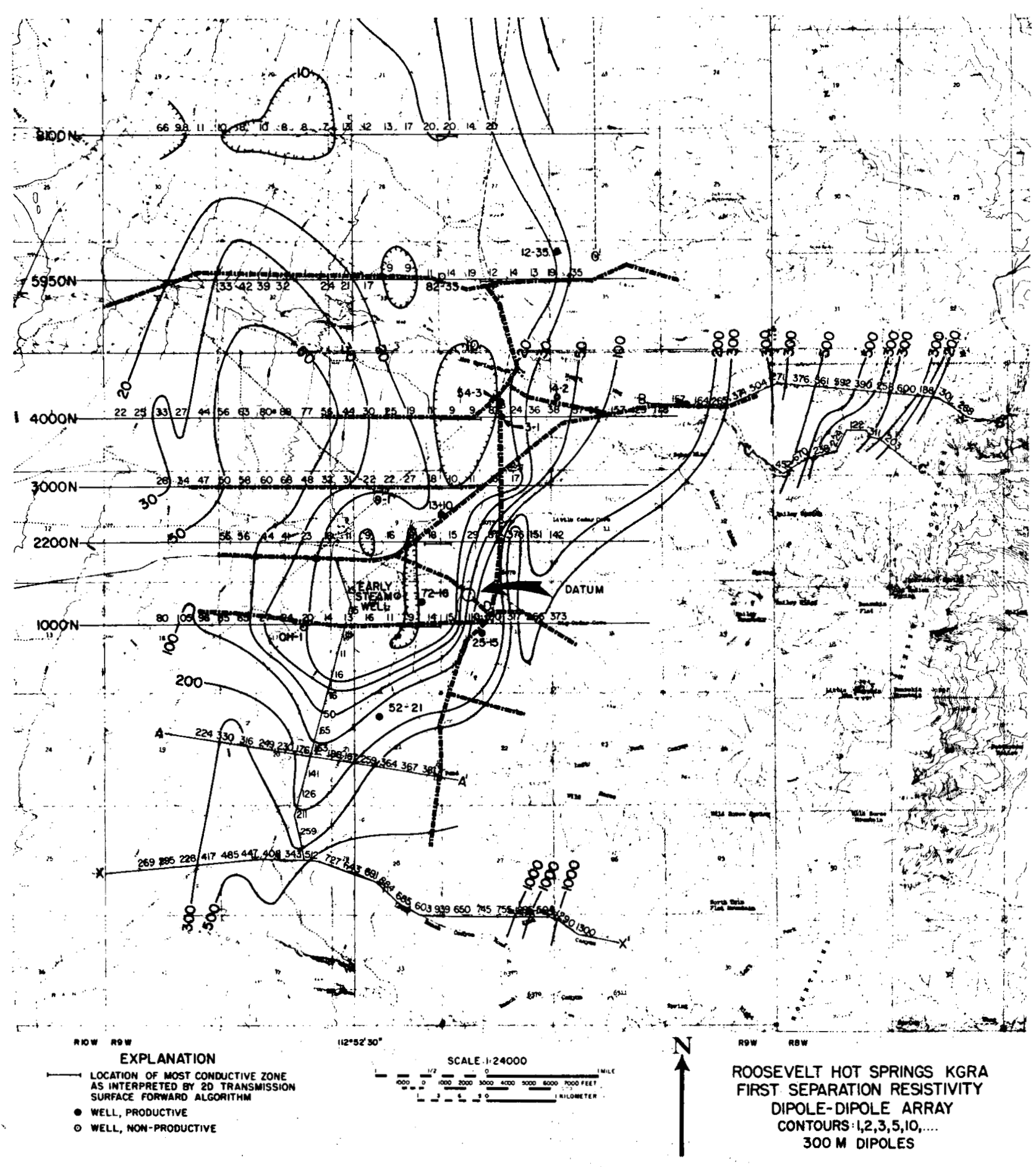

Figure 2 


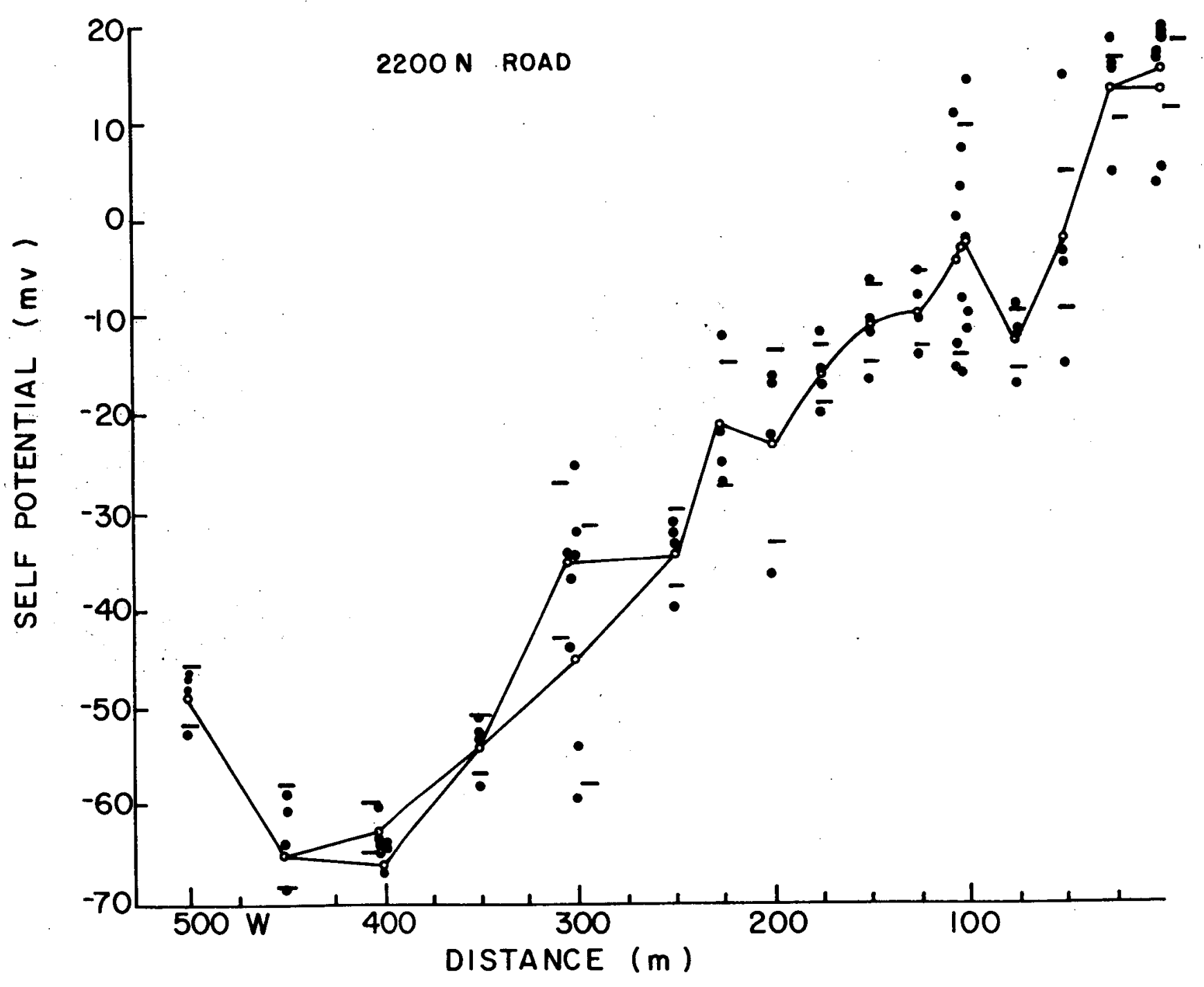

Figure 3 


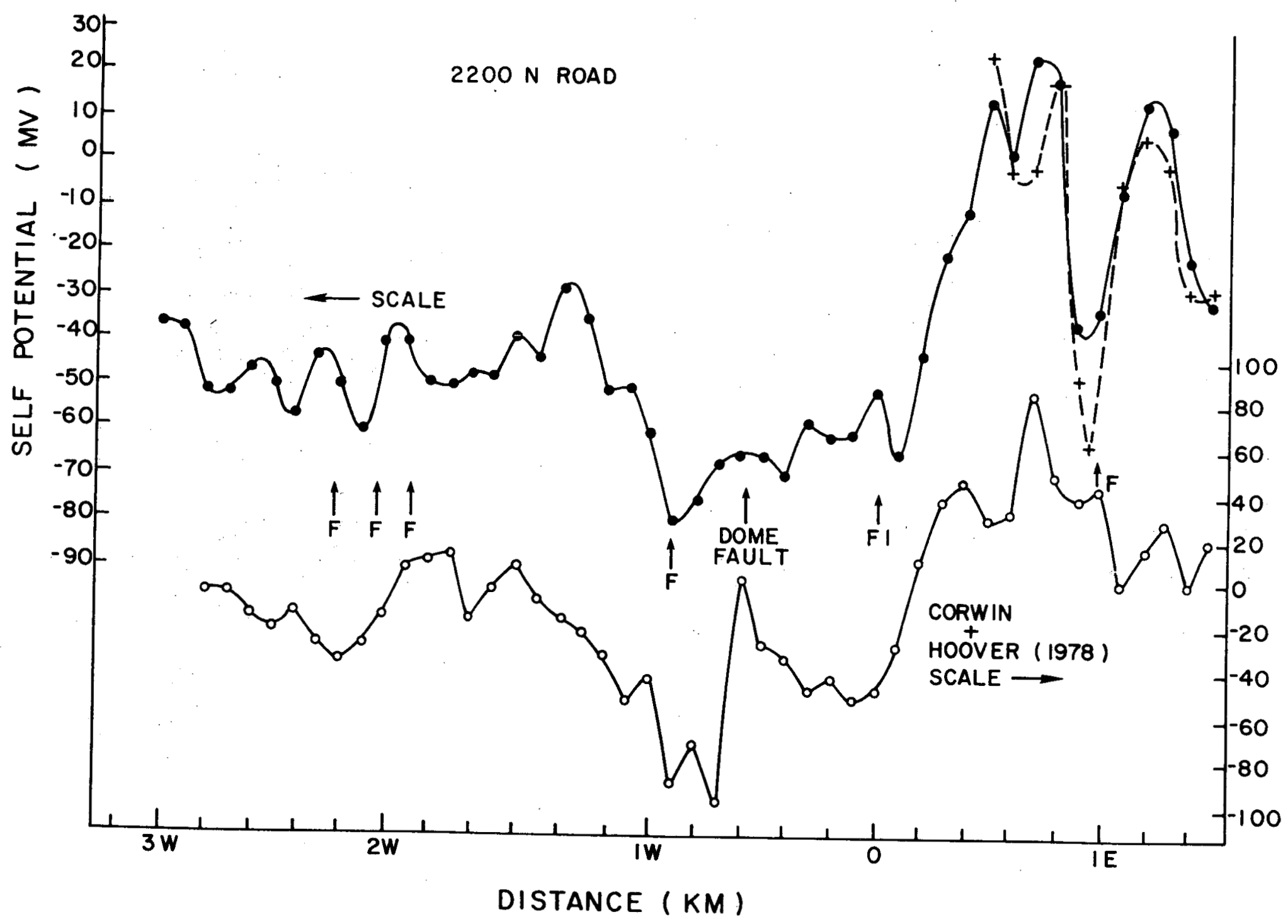

Figure 4 


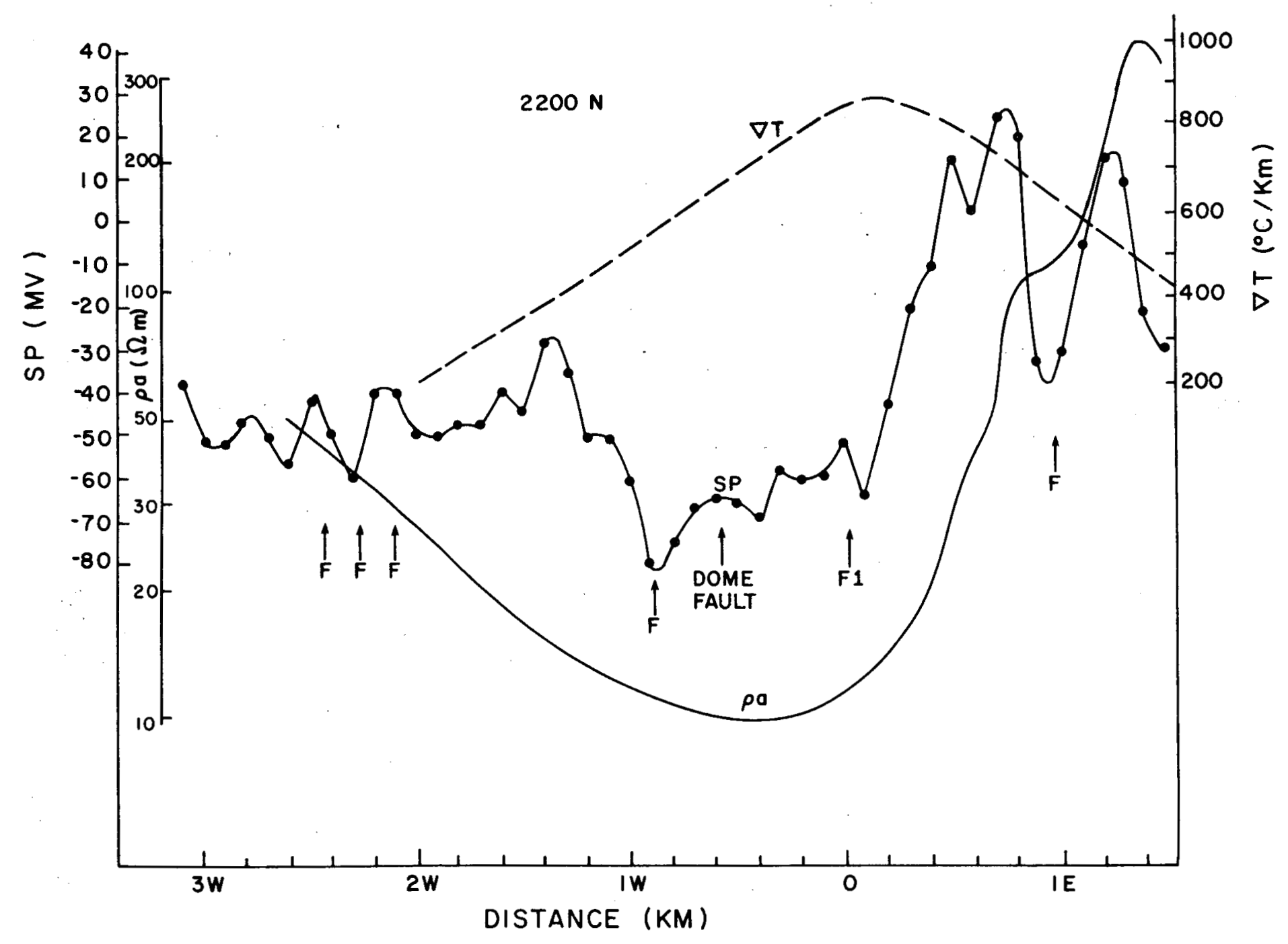

Figure 5 


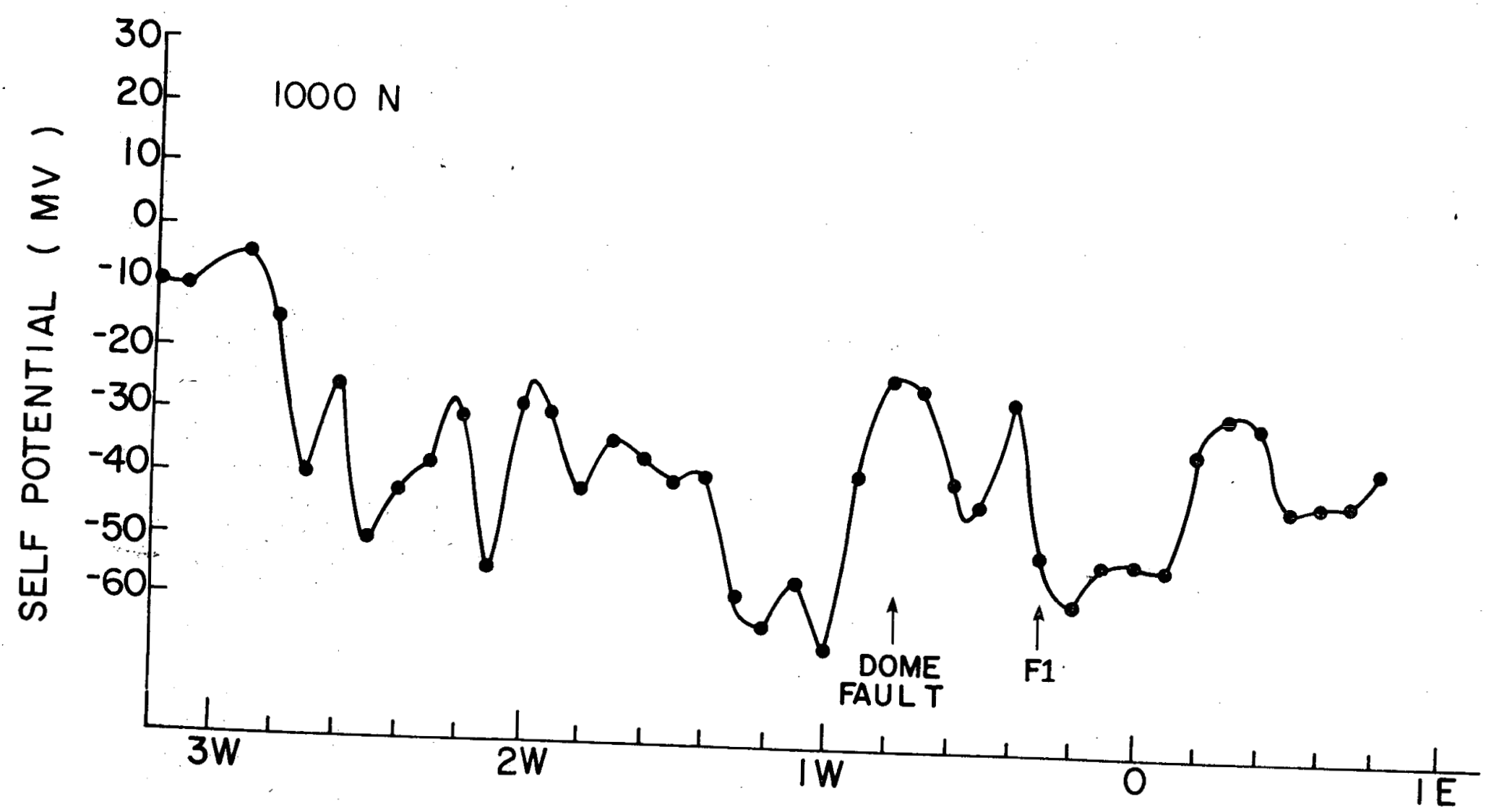

Figure 6 


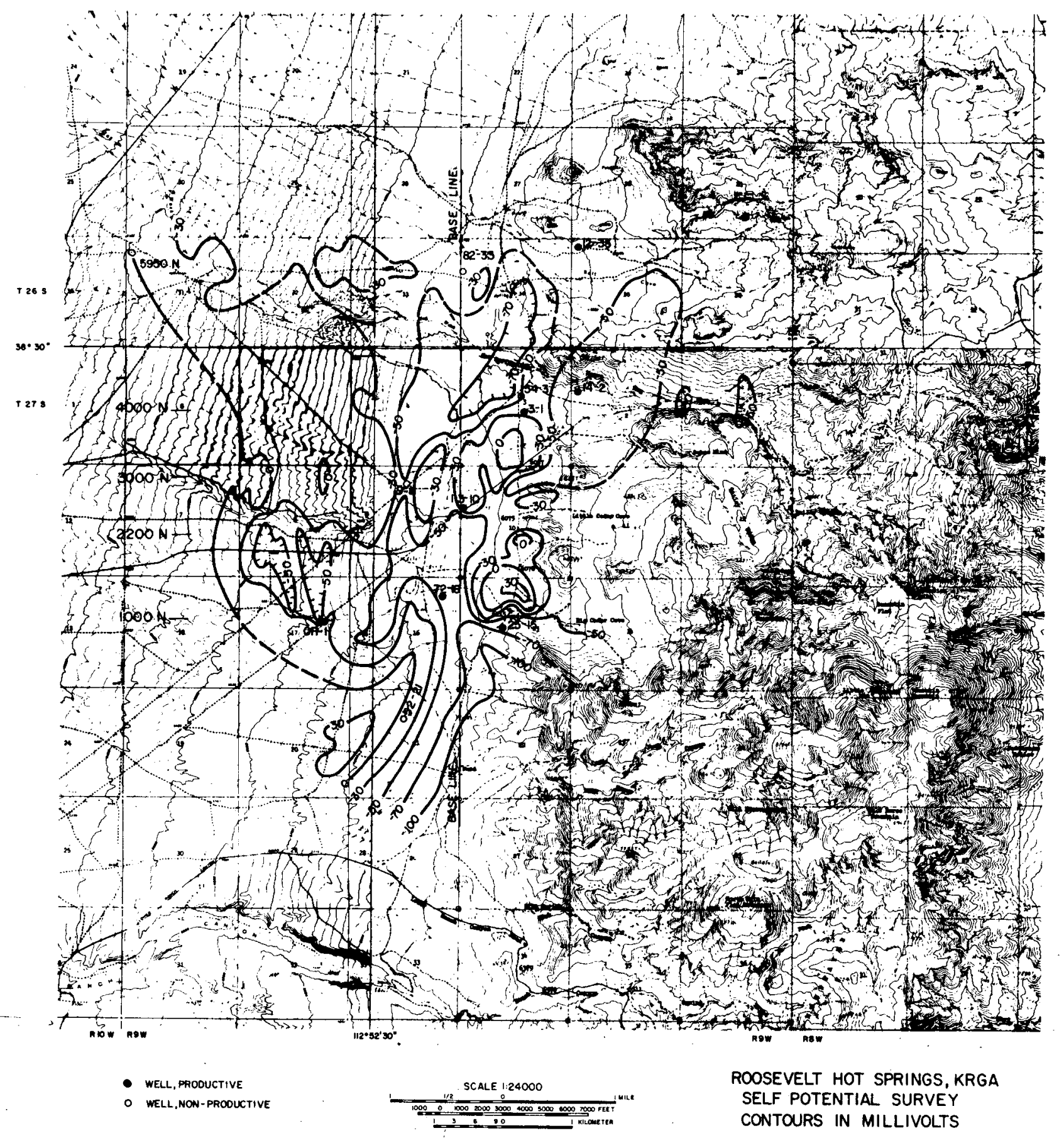

Figure 7 


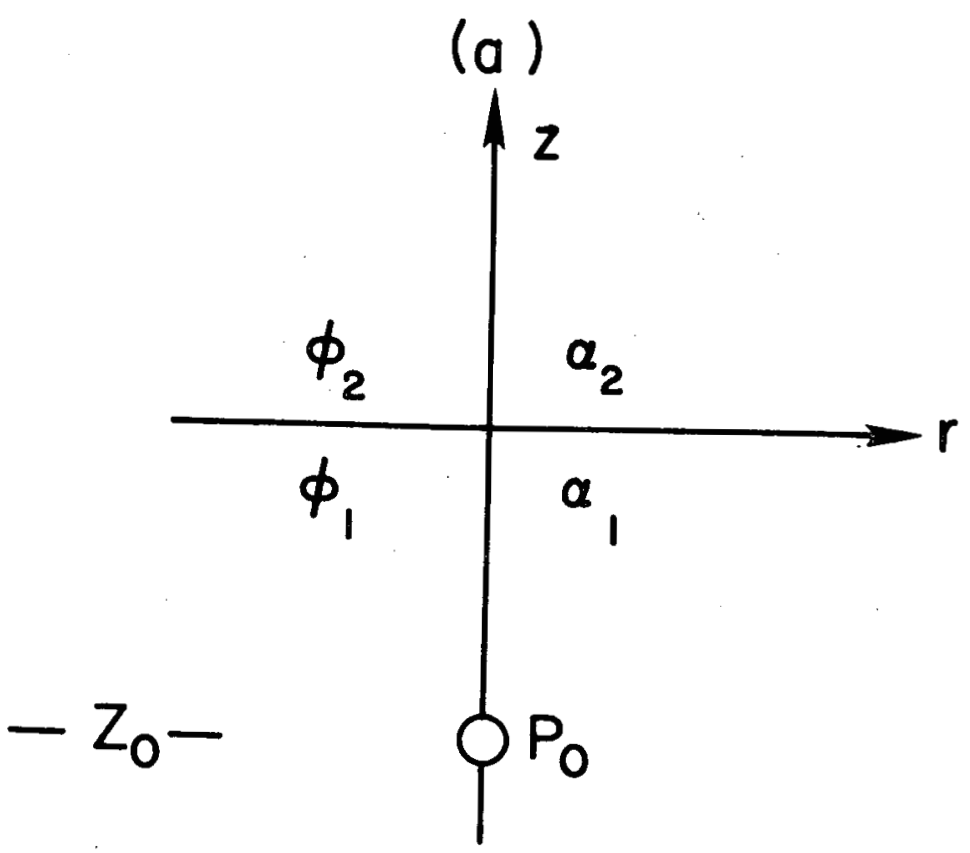

Figure 1a

(b)

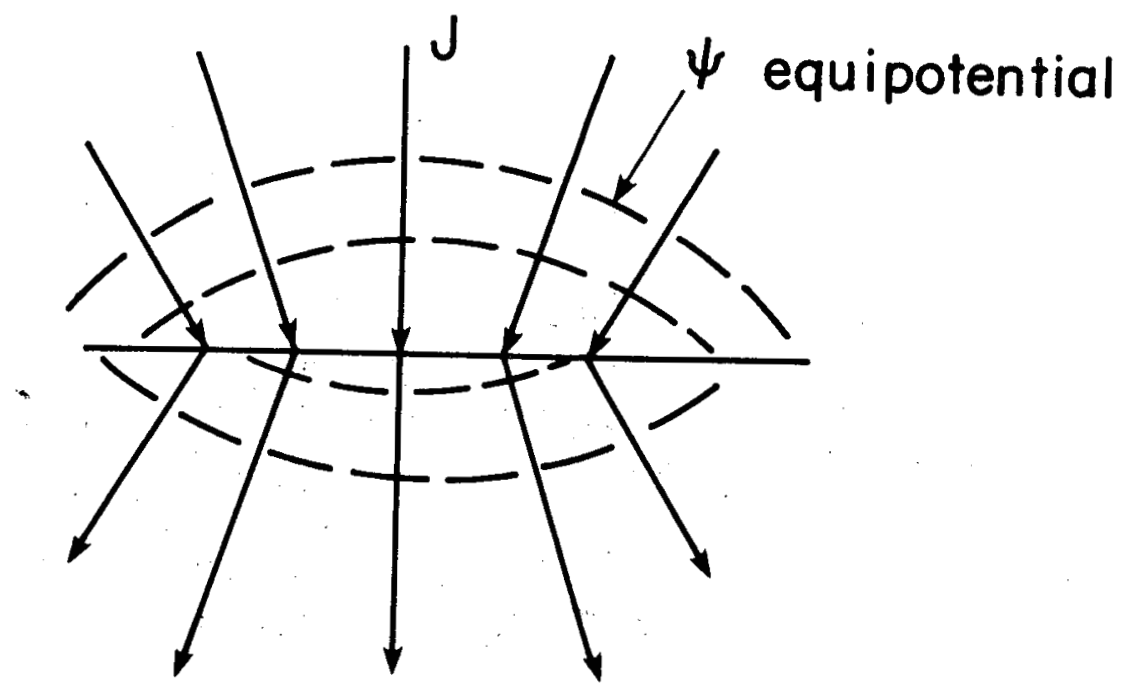

Figure 1b 
(a)

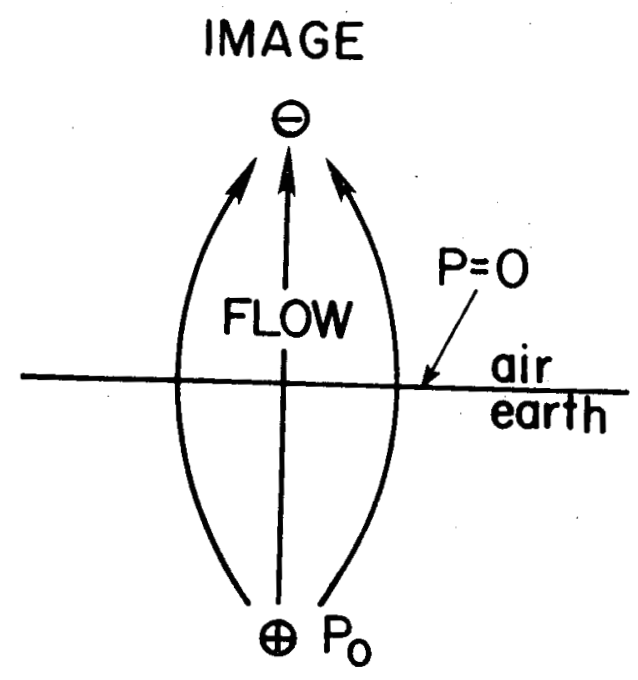

PRESSURE

SOURCE

Figure $2 a$

(c)

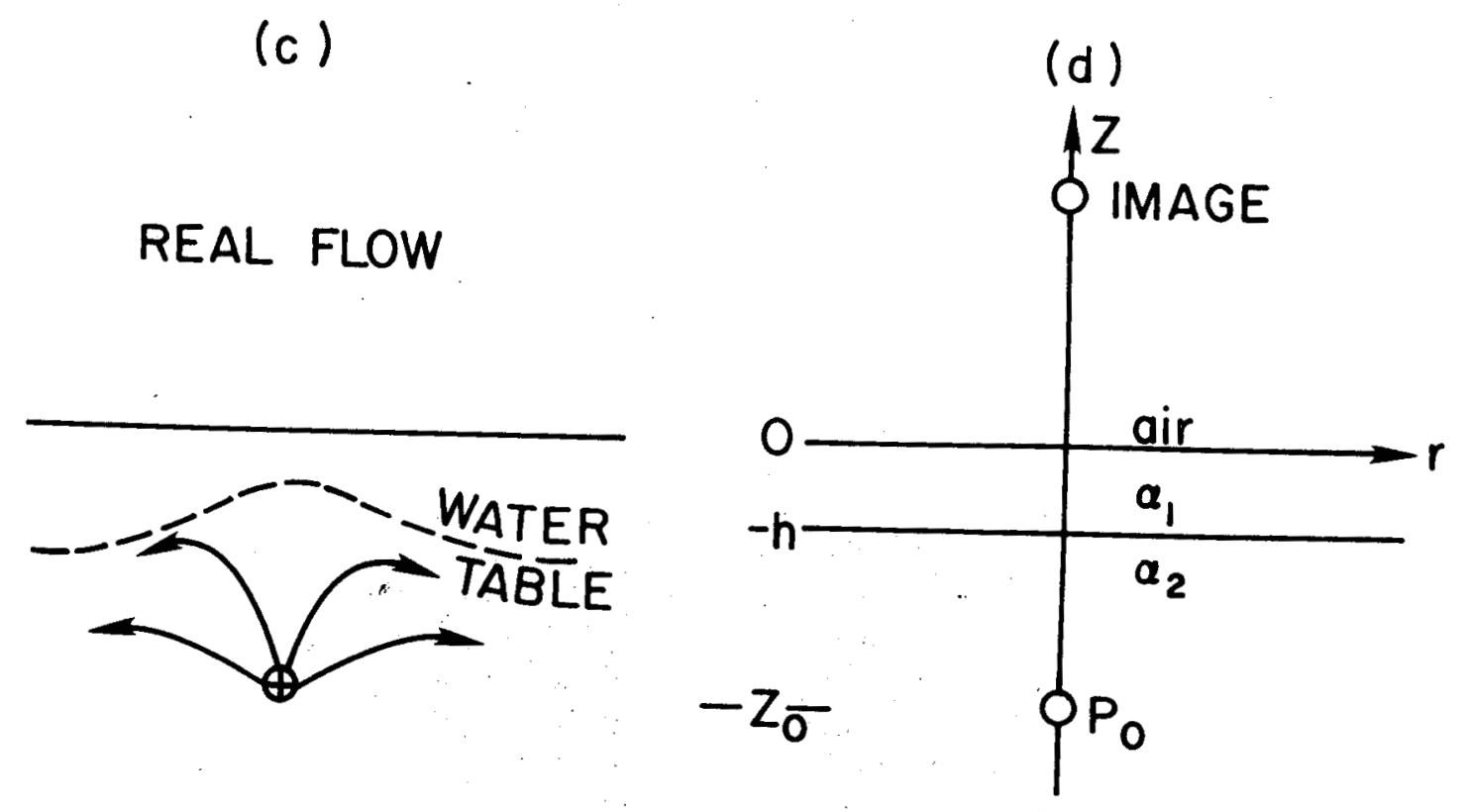

(b)

IMAGE

$\oplus$

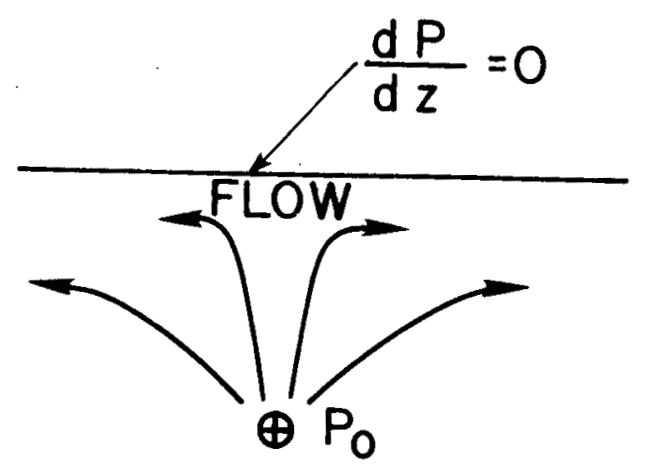

PRESSURE SOURCE

Figure 2b

Figure 2c

Figure 2d 
(a)

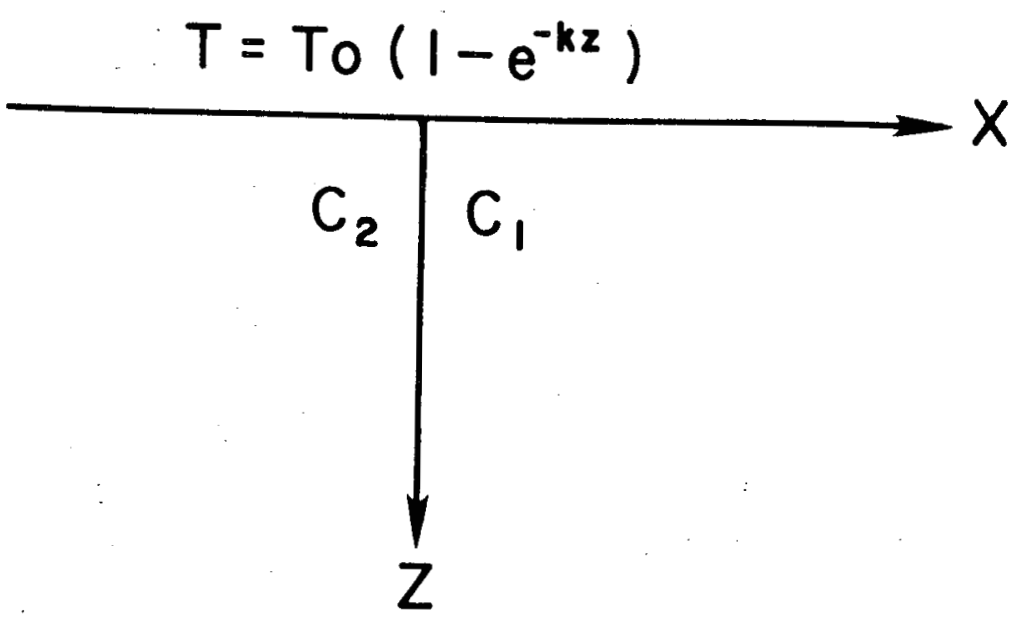

Figure $3 a$

(b)

$\phi /\left(C_{1}-C_{2}\right) T_{0}$

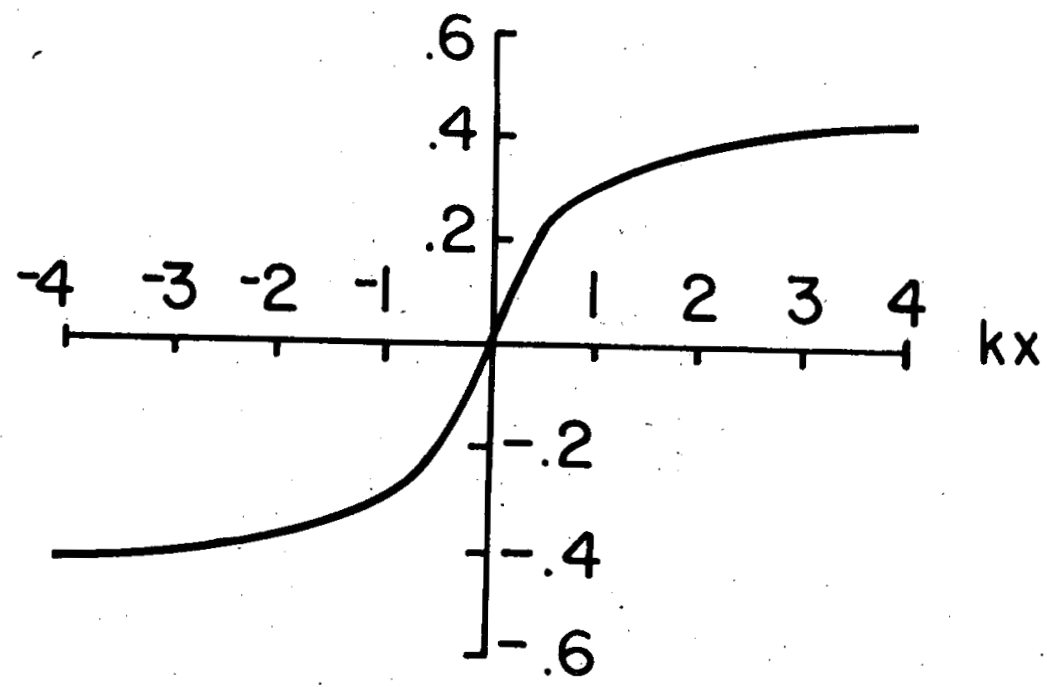

Figure 3b 
David N. Anderson

Executive Director

Geothermal Resources Council

P.0. Box 1033

Davis, CA 95616

Dr. James K. Applegate

Department of Geology

Boise State University

Boise, ID 83725

Mr. Sam Arentz, Jr., President

Steam Corporation of America

1720 Beneficial Life Tower

Salt Lake City, UT 84111

Dr. David J. Atkinson

Hydrothermal Energy Corp. 2519 Horseshoe Canyon Drive

Los Angeles, CA 90046

Dr. Carl F. Austin.

c/o Geothermal Technology

Code 2661, NWC

China Lake, CA 93555

Mr. Lawrence Axtell

Geothermal Services, Inc.

10072 Willow Creek Rd.

San Diego, CA 92131

Mr. Larry Ball

DOE

Division of Geothermal Energy

3rd Floor, MS 3122C

20 Massachusetts Ave., N.W.

Washington, DC 20545

Mr. Ronald Barr

Earth Power Corporation

P.0. Box 1566

Tulsa, OK 74101

Dr. Rudolf A. Black

DOE

Dir. of Div. of Geothermal Energy

3rd Floor, MS 3122C

20 Massachusetts Ave., N.W.

Washington, DC 20545
Dr. David D. Blackwell

Southern Methodist University

Department of Geological Sciences

Dallas, TX 75275

Dr. Marvin G. Bloomquist

Research Associate

Mobil Research \& Develop. Corp.

Research Dept.

P.0. Box 900

Dallas, TX 75221

Dr. Gunnar Bodvarsson

Oregon State University

School of Oceanography

1377 N.W. Alta Vista Dr.

Corvallis, OR 97330

Mr. C. M. Bonar

Director, Geothermal Projects

Atlantic Richfield Co.

P.0. Box 1829

Dallas, TX 75221

Roger L. Bowers

Hunt Energy Corp.

2500 lst Nat 1 Bank Bldg.

Dallas, TX 75202

Cerald Brophy

DOE

Division of Geothermal Energy

3rd Floor, MS 3122C

20 Massachusetts Ave., N.W.

Washington, DC 20545

Mr. William D. Brumbaugh

Geophysics Bldg., Room 12

Interpretation Group

Conoco

Ponca City, OK 74601

Mr. Glen Campbell

Geothermal Supervisor

Gulf Min. Resource Company

1720 South Bell Aire St.

Denver, CO 80222

Tom Cassel

Fels Center of Govt.

Univ. of Pennsylvania

39 th \& Walnut Streets

Philadelphia, PA 19104 
Ray Chantler

McCulloch 0il Corp.

10880 Wilshire Blvd.

Los Angeles, CA 90024

Dr. Bob Christiansen

U.S. Geological Survey

345 Middlefield Road

Men lo Park, CA 94205

Eugene V. Ciancanelli

Consulting Geologist

12352 Escala Drive

San Diego, CA 92128

Dr. Jim Combs

Geothermal Services, Inc.

10072 Will ow Creek Rd.

San Diego, CA 92131

Mr. F. Dale Corman, President

O'Brien Resources, Inc.

49 Touss in Avenue

Kentfield, CA 94904

Dr. R. Corwin

Dept. Eng. Geoscience

University of California A Berkeley

Berkeley, CA 94720

Mr. Ritchie Coryell

Program Manager

National Science Foundation

1800 G Street, N.W.

Washington, DC 20050

Dr. Gary Crosby

Phillips Petroleum Company

71-C PRC

Bartlesville, OK 74003

Mr. W. L. D'01ier

Geothermal Operations

Thermal Power Co.

601 California Street

San Francisco, CA 94108

Mrs. Katie Dixon

3781 Lois Lane

Salt Lake City, UT 84117
Mr. William Dolan

Chief Geophysicist

Amax Exploration Inc.

4704 Harlan Street

Denver, C0 80212

John E. Dooley

R. F. Smith Corp.

552 E. 3785 S.

Salt Lake City, UT 84106

Robert C. Edmiston

Anadarko Production Co.

P.0. Box 1330

Houston, TX 77001

Mr. Samuel M. Eisenstat, President Geothermal Exploration Co., Inc. 400 Park Ave.

New York City, NY 10022

Dr. Val A. Finlayson

Research Engineer

Utah Power and Light Company

1407 West North Temple

Salt Lake City, UT 84110

Mr. Milton Fisher

295 Madison Avenue

New York City, NY 10017

Mr. Ron Forrest, Geologist

Phillips Petroleum Co.

P.0. Box 858

Milford, UT 84751

Ken Fournier

Union 0 il

Union Research Center

Box 76

Brea, CA 92621

Dr. Frank Frischknecht

Box 25046, Denver Federal Center

U.S. Geological Survey

Denver, CO 80225

Robert Furgerson

Argonaut Enterprises

1480 Hoyt Street

P.0. Box 26330

Denver, C0 80226 
Mr. Gary Galyardt, Geologist

U.S. Geological Survey

MS 602

Box 25046, Federal Center

Denver, CO 80225

Ms. N. Sylvia Goeltz

UV Industries, Inc.

19th Floor, University Club Bldg.

Salt Lake City, UT 84111

Dr. N. E. Goldstein

Lawrence Berkeley Laboratory

Building 90

University of California, Berkeley

Berkeley, CA 94720

Mr. Steven M. Goldstein

The Mitre Corporation

Metrek Division

1820 Dolley Madison Blvd.

McLean, VA 22101

Mr. Bob Greider, V. P. Exploration

Intercontinental Energy Co.

P.0. Box 17529

Denver, C0 80217

Mr. J. H. Hafenbrack

Exxon Co. USA

P.0. Box 120

Denver, C0 80201

$\mathrm{Mr}$. Dee C. Hansen

Utah State Engineer

442 State Capitol

Salt Lake City, UT 84114

Richard J. Haren

CSIRO Minerals Research Labs

Division of Mineral Physics

P.0. Box 136

North Ryde, N.S.W. 2113

AUSTRALIA

Dr. Norman Harthill

Executive Vice President

Group Seven, Inc.

9250 W. 5th Ave.

Lakewood, C0 80226

Dan E. Haymond

P.0. Box 239

Salt Lake City, UT 84110
Mr. Jack Von Hoene

Davon, Inc.

250 North 100 West

Milford, UT 84751

George Hopkins

Geotronics Corp.

10317 McKalla Place

Aust in, TX 78758

Mr. Gerald W. Huttrer, Sr. Geologist

Intercontinental Energy Corporation

7503 Marin Dr., Suite 1-C

Englewood, C0 80110

Mr. Laurence $P$. James

2525 South Dayton Way \#1406

Denver, C0 80231

Dr. George R. Jiracek

Department of Geology

University of New Mexico

Albuquerque, NM 87131

Mr. Richard L. Jodry

P.0. Box 941

Richardson, TX 75080

Dr. Paul Kasameyer

Lawrence Livermore $L a b, L-224$

P.0. Box 808

Livermore, CA 94550

Dr. George Keller

Professor and Head

Department of Geophysics

Colorado School of Mines

Golden, CO 80401

Mr. James B. Koenig

Geothermex

901 Mendocino Avenue

Berkeley, CA 94704

Dr. George A. Kolstad

DOE

Mail Stop J309

Germantown, MD 20545

Dr. Mark Landisman

Professor of Geophysics

University of Texas, Dallas

Box 688

Richardson, TX 75080 
A. W. Laugh1 in, Group Leader

Geothermal Programs, Geol Appl Grp G-9

Los Alamos Scient ific Laboratory

P.0. Box 1663

Los Alamos, NM 87545

Mr. Guy W. Leach, Geologist

0il Development Company of Texas

Box 12053, American Natl Bank Bldg.

Amarillo, TX 79101

Mr. Dick Lenzer

Phillips Petroleum Company

P.0. Box 239

Salt Lake City, UT 84110

Earth Sciences Division Library

Building 90

University of California

Lawrence Berkeley Laboratory

1 Cyclotron Road

Berkeley, CA 94720

Don R. Mabey

U.S. Geological Survey

Rm. 468, Post office Bldg.

Salt Lake City, UT 84101

Charles William Mase

Geothermal Studies

Mail Stop 18

U.S. Geological Survey

345 Middlefield Road

Menlo Park, CA 94025

Mr. Skip Matlick

Republic Geothermal

P. 0. Box 3388

Santa Fe Springs, CA 90670

James 0. McClellan, President

Geothermal Electric Systems Corp.

5278 Pinemont Drive, Suite A-150

Salt Lake City, UT 84107

Dr. Robert B. McEuen

Woodward Clyde Consultants

Three Embarcadero Center, Suite 700

San Francisco, CA 94111

Mr. Don C. McMillan

Utah Geological \& Mineral Survey

606 Blackhawk Way, Research Park

Salt Lake City, UT 84108
Dr. Tsvi Meidav

Consultant

40 Brookside Ave.

Berkeley, CA 94705

Mr. Frank G. Metcalfe, Pres. Geothermal Power Corporation 1127 Grant Ave., Suite 6

P.0. Box 1186

Novato, CA 94947

Dr. Martin Molloy

U.S. DOE

133 Broadway

0ak land, CA 94612

Dr. Frank Morrison

Professor of Geophysics Eng.

University of California

Hearst Mining Building

Berkeley, CA 94720

Dr. L. J. Patrick Muffler

U.S. Geological Survey

345 Middlefield Road

Menlo Park, CA 94205

Mr. Clayton Nichols

DOE

Division of Geothermal Energy

Idaho Operations Office

550 . Second Street

Idaho Falls, ID 83401

Mr. Carel otte

President of Geothermal Division Union 0il Company

P.0. Box 7600

Los Angeles, CA 90051

Dr. Wayne Peeples

Dept. of Geological Sciences

Southern Methodist University

Dallas, TX 75221

Mr. C. R. Possell

General Ener-Tech, Inc.

4842 Viane Way

San Diego, CA 92110

Dr. Alan 0. Ramo

Sunoco Energy Development Co.

12700 Park Central P1.

Suite 1500, Box 9

Dallas, TX 75251 
Marshall Reed

DOE

Division of Geothermal Energy

3rd Floor, MS 3122C

20 Massachusetts Ave., N.W.

Washington, DC 20545

Robert S. Reed

Thermogenics, Inc. c/o Hughes Aircraft

Centinela and Teale

Culver City, CA 90230

Dr. Robert W. Rex, President

Republic Geothermal, Inc.

11823 E. Slauson Ave., Suite 1

Santa Fe Springs, CA 90670

Ms. Barbara Ritzma

Science \& Engineering Department

Marriott Library

$159 \mathrm{ML} i$, CAMPUS

Dr. Jack Salisbury

DOE

Division of Geothermal Energy

3rd Floor, MS 3122C

20 Massachusetts Avenue, N.W.

Washington, DC 20545

Dr. Konosuke Sato

Metal Mining Agency of Japan

Tokiwa BIdg.

1-24-14 Toranomon

Minato-Ku, Tokyo

JAPAN

Dr. John V. A. Sharp

Hydrosearch, Inc.

333 Flint Street

Reno, NV 89501

Mr. Wayne Shaw

Getty 0il Company

P.0. Box 5237

Bakersfield, CA 93308

Mr. Gregory L. Simay

City of Burbank - Public Service Dept.

164 West Magnolia BTvd.

Burbank, CA 91503
Mr. W. P. Sims

DeGolyer and MacNaughton

One Energy Square

Dallas, TX 75206

Dr. H. W. Smith

Department of Electrical Engineering University of Texas, Austin

Aust in, TX 78712

Màrty Steyer

Nat1 Geothermal Info Resource

Lawrence Berkeley Lab, 50A-0143A

Univ. of California

Berkeley, CA 94720

Mr. Paul V. Storm

California Energy Company, Inc.

Wells Fargo Bldg., Suite 300

P.0. Box 3909

Santa Rosa, CA 95402

Dr. Chandler Swanberg

New Mexico State University

P.0. Box 4408

University Park Dr.

Las Cruces, NM 88003

Dr. Charles M. Swift, Jr.

Chevron $0 i 1$ Co.-Minerals Staff

P.0. Box 3722

San Francisco, CA 94105

Dr. Bernard Tillement

Aquitaine Co. of Canada

2000 Aquataine

5405 th Avenue, S.W.

Calgary, Alberta

Canada 2TP OMA

David D. Tillson

Washington Public Power Supply System

P.0. Box 968

Richland, WA 99352

Dr. Ronald Toms

DOE

Division of Geothermal Energy 3rd Floor, MS 3122C

20 Massachusetts Avenue, N.W. Washington, DC 20545 
Alan Tratner

Geothermal World Corp.

18014 Sherman Way, Suite 169

Reseda, CA 91335

Dr. John Tsiaperas

Shell 0il Company

Box 831

Houston, TX 77001

Dr. A. F. Veneruso

Geothermal Technology Division 5736

Sandia Laboratories

Albuquerque, NM 87115

Dan Vice

555 Park Lane

Billings, MT 59102

Dr. James R. Wait

Rx7, Room 242, RB1

U.S. Dept. of Commerce

National Oceanic \& Atmospheric Admin.

Environmental Research Labs

Boulder, CO 80302

John Walker

DOE

Division of Geothermal Energy

3rd Floor, MS 3122C

20 Massachusetts Ave., N.W.

Washington, DC 20545

Mr. D. Roger Wall, Geologist

Geothermal Resources Division

Aminoil USA, Inc.

1250 Coddingtown Center

Santa Rosa, CA 95401

Dr. Paul Walton, President

American Geological Enterprises, Inc. 1102 Walker Bank Bldg.

Salt Lake City, UT 84111

J. L. Wilson

4321 Post Road

San Diego, CA 92117

Ed Witterholt

City Services 0 il Co.

Energy Research Lab

Box 50408

Tulsa, OK 74150
Mr. William B. Wray, Jr.

Vancott, Bagley, Cornwall \& McCarthy

141 East 1st South

Salt Lake City, UT 84111

Dr. Paul C. Yuen

University of Hawai a Manoa 2540 Dole Street, Holmes 240

Honolulu, HI 96822

Dr. S. H. Yungul

Chevron Resources Co.

P.0. Box 3722

San Francisco, CA 94119

Dr. Elliot J. Zais

Elliot Zais \& Associates

7915 N.W. Siskin Dr.

Corvallis, OR 97330

Kenneth L. Zonge

Zonge Engineering \& Res.

5634 E. Pima Street

Tucson, AZ 85712 